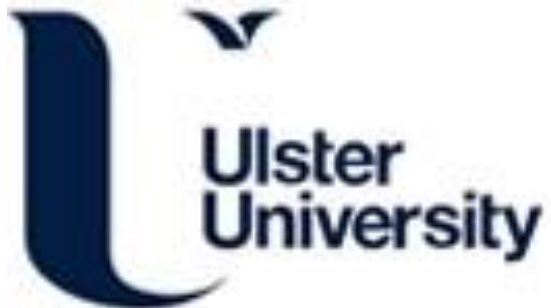

\section{Towards a microfluidic based rapid amylase assay system}

Holmes, RJ., Summesgil, P., Ryan, T., Treve Brown, BJ., Mockbil, A., Grieve, BD., \& Fielden, PR. (2009). Towards a microfluidic based rapid amylase assay system. Journal of Food Science, 74(6), N37-N43. https://doi.org/10.1111/j.1750-3841.2009.01235.x

Link to publication record in Ulster University Research Portal

\section{Published in:}

Journal of Food Science

Publication Status:

Published (in print/issue): 01/01/2009

DOI:

10.1111/j.1750-3841.2009.01235.x

\section{Document Version}

Publisher's PDF, also known as Version of record

\section{General rights}

Copyright for the publications made accessible via Ulster University's Research Portal is retained by the author(s) and / or other copyright owners and it is a condition of accessing these publications that users recognise and abide by the legal requirements associated with these rights.

\section{Take down policy}

The Research Portal is Ulster University's institutional repository that provides access to Ulster's research outputs. Every effort has been made to ensure that content in the Research Portal does not infringe any person's rights, or applicable UK laws. If you discover content in the Research Portal that you believe breaches copyright or violates any law, please contact pure-support@ulster.ac.uk. 


\title{
Toward a Microfluidic-Based Rapid Amylase Assay System
}

\author{
Richard J. Holmes, Philip Summersgil, Timothy Ryan, Bernard J. Treves Brown, \\ Amal Mockbil, Bruce D. Grieve, and Peter R. Fielden
}

\begin{abstract}
This article describes work into a prototype system for the assay of amylase, using microfludic technologies. The new system has a significantly shorter cycle time than the current laboratory methods, which generally use microtitre plates, yet is capable of generating significantly superior results. As such, we have shown that sensitivity is enhanced by a factor of 10 in the standard assay trials, and by a factor of 2 in the real-sample lab trials. In both assays, the use of a microreactor system reduced the reaction time by a factor of 6.2 , from 20 min incubation to 3.2 min. Basing the conclusion on the Megazyme Cerealpha Standard Method, and using the Cerealpha units as a measure of assay efficiency, the typical response for the microfluidic assay was shown to be $1.0 \times 10^{-3} \mathrm{CU} / \mathrm{mL}$ (standard deviation [SD] $2.5 \times 10^{-4} \mathrm{CU} / \mathrm{mL}$ ), compared to $2.56 \times 10^{-4} \mathrm{CU} / \mathrm{mL}$ (SD $5.94 \times 10^{-5} \mathrm{CU} / \mathrm{mL}$ ) for the standard macroassay. It is believed that this improvement in the reaction schematics is due to the inherent advantages of microfluidic devices such as superior mixing, higher thermal efficiency, and enhanced reaction kinetics.

Keywords: amylase, analysis, enzyme assay, instrumentation, microfluidics
\end{abstract}

\section{Introduction}

\section{$\alpha$-Amylase and bioprocessing}

$\alpha$-Amylase is a starch hydrolase which can hydrolyze internal $\alpha-1,4$ glycoside bonds in polysaccharides or oligosaccharides, and cleave the latter into glucose, maltose, maltotriose (G3), or dextrin. $\alpha$-Amylase plays an important role in many bioprocesses (Cochran and others 2008), where the level of $\alpha$-amylase in cereal grains (Sirou and others 1990; Gibson and others 1997; Rader and others 1998) and products significantly affects the industrial exploitation of these commodities. In breadmaking, the level of $\alpha$-amylase must be sufficient to produce saccharides, which can be consumed by yeast, but not so high as to cause excessive starch dextrinization that can lead to sticky crumb and problems in processing (Gibson and others 1994).

In the brewing industry, the level of malt $\alpha$-amylase is a key quality parameter (Robinson and others 2007). The need for a rapid, specific, convenient, and reliable method for the assay of $\alpha$-amylase by plant breeders, bakers, maltsters, brewers, and enzyme manufacturers, and users is well documented (Kaufman and Tletz 1980; Sadowski and others 1986; Min and others 1995; Bogdanovic and others 2006; Maeda and others 2008).

For bioreactor systems, insufficient levels of amylase in a feedstock can lead to fouling of the process plant, on occasions forcing a shutdown to facilitate cleaning (Mojovic and others 2006). The addition of excess amylase to guard against this is a costly exercise, as

MS 20080976 Submitted 12/4/2008, Accepted 5/11/2009. Authors Holmes, Treves Brown, and Fielden are with Manchester Interdisciplinary Bioscience Centre, School of Chemical Engineering and Analytical Science, The Univ. of Manchester, 131 Princess St., Manchester, M1 7DN, U.K. Authors Summersgil and Ryan are with Epigem Ltd., Malmo Court, Kirkleatham Business Park, Redcar, TS10 5SQ, U.K. Author Mockbil is with Manchester Interdisciplinary Bioscience Centre, Faculty of Life Sciences, The Univ. of Manchester, 131 Princess St., Manchester, M1 7DN, U.K. Author Grieve is with Syngenta Sensors Univ. Innovation Centre, School of Electrical and Electronic Engineering, The Univ. of Manchester, Sackville St., P.O. Box 88 , Manchester, M60 1QD, U.K. Direct inquiries to author Holmes (E-mail: richard.holmes@manchester.ac.uk). it is expensive (Gogoir and others 1987; Kaneko and others 2005; Ebrahimi and others 2008) and much of the enzyme can be wasted if the levels are not carefully monitored (Jeon and others 2008).

Megazyme Intl. Ireland Ltd (Wicklow, Ireland) has developed a microtitre plate assay with a custom reagent mixture, marketed as Amylase HR, for determining enzyme activity in a given sample by their "Cerealpha" method. In the Cerealpha procedure an aliquot of a cereal flour extract or fermentation, broth is incubated with a reagent/buffer solution and the reaction is terminated by the addition of $\mathrm{pH} 11$ phosphate buffer. The $\mathrm{pH}$ change generates a colorimetric shift, facilitating detection via absorbance at $410 \mathrm{~nm}$; this is directly related to the level of $\alpha$-amylase in the sample (McCleary and Sheehan 1987; Sheehan and McCleary 1988; Foo and Bais 1998).

The reagent is a mixture of a nonreducing end blocked p-nitrophenyl maltoheptasoide (BPNPG7) and excess levels of amyloglucosidase and $\alpha$-glucosidase. On hydrolysis of the BPNPG7 by $\alpha$-amylase, the excess quantities of amyloglucosidase and $\alpha$-glucosidase present in the mixture, give instantaneous and quantitative hydrolysis of the p-nitrophenyl maltosaccharide fragment to glucose and free p-nitrophenol ( $\alpha$-Amylase Assay Procedure [Cerealpha method]: Icc Standard nr 303, 2008).

\section{Application of microreactor technology to amylase assays}

The field of microreactors and microfluidics is one that offers significant advantages over macroreactors in terms of yield and efficiency; additionally, a smaller-sized device means reduced consumption of materials and power, and therefore a reduction in the volumes of reagents required and the generation of waste materials. Additionally, standardized conditions can be maintained, and uniformity of mixing can be rapidly established (Craston and Cowen 1996; Cowen 1999; de Mello and Wooten 2002; Pennathur 2008).

Reactions and mixing benefit from miniaturization since the different components are in closer proximity and therefore interact more quickly with the resulting reactions being more 
efficient (Doku and Haswell 1998). It has been demonstrated that miniaturized reaction systems offer far better yields than could be obtained in larger systems (Greenway and others 2000).

In fact, recent studies of the phenomena of microfluidic mixing suggest that this improvement in mixing efficiency and subsequent increase in reaction yield is a direct result of the significantly smaller Reynolds numbers $\left(<10^{2}\right)$, when contrasted to macroscale mixing, where Reynolds numbers are in the order of $>10^{3}$. This entails that mixing in microreactors is determined by laminar flow and diffusion, rather than by turbulence as seen in larger systems (DeMello 2006). By further utilizing chaotic advection in microfludic reactors, the introduction of obstacles to flow or modification of channel geometries-as seen with the interdigitated micromixer approach shown in this study (Figure 1), in turn enhances the mixing efficiency of a low Reynolds number flow in a microreactor device (Stroock 2002).

As such, an experimental setup was conceived to illustrate the benefits of moving to a microfluidic reactor system for the amylase assay. The intent of the experimental procedure was to replicate the larger-scale assay, using a constant flow microreactor device, and offer a comparison of the 2 systems.

\section{Materials and Methods}

\section{Reagent preparation}

The Cerealpha reagent was purchased from Megazyme Intl. and was prepared as instructed, with $10 \mathrm{~mL}$ DI water added to the dried reagent-which was subsequently stored in a refrigerator until required.

The assay buffer was prepared as per the Megazyme instructions, and contained $23.2 \mathrm{~g}$ of maleic acid, $11.6 \mathrm{~g}$ of sodium chloride, $0.6 \mathrm{~g}$ of calcium chloride, $0.2 \mathrm{~g}$ of sodium azide, and bovine serum albumen (BSA) at a concentration of $0.5 \mathrm{mg} / \mathrm{mL}$. Approximately 2 liters of assay buffer were prepared.

An $\alpha$-amylase standard solution was prepared using $\alpha$-amylase from Bacillus sp. Serial dilutions of the concentrated solution were used to give a final standard concentration of $0.005 \%(\mathrm{v} / \mathrm{v})$ $\alpha$-amylase.

Finally, the reaction is terminated by the use of a $1 \%(v / v)$ sodium triphosphate solution at $\mathrm{pH} 11$.

All reagents were purchased from Sigma-Aldrich Co. Ltd (Dorset, U.K.).

\section{Experimental design}

Initially, replicates of the standard biochemical assay were conducted to provide a baseline for the microreactor system. This comprised 2 components, the blank determination and the macroassay. Four blank assays and 12 macroassays were prepared in Treff tubes.
Each assay consisting of $0.2 \mathrm{~mL}$ of the $\alpha$-amylase standard and $0.2 \mathrm{~mL}$ of the $\mathrm{HR}$ reagent, which was incubated for $20 \mathrm{~min}$ at $60^{\circ} \mathrm{C}$, after which $3 \mathrm{~mL}$ of the $1 \%$ phosphate stop reagent were added to raise the $\mathrm{pH}$ and terminate the enzyme reaction. This released the para-nitrophenol (PNP) into solution, and produced a color shift at $400 \mathrm{~nm}$ that was measured using the Ocean Optics Spectrometer. The blank assays were conducted with the stop reagent present for the incubation period.

The microreactor assay was conducted in a similar manner, with the amylase standard and the HR reagent added upstream of the incubators, and the stop reagent added to terminate the reaction.

\section{Microreactor system}

The microreactor board was purchased from Epigem Ltd. (Redcar, U.K.) designed based on the Fluence breadboard microfludics systems technology. This system consisted of a number of interchangeable components including mixers, fixed volume serpentine channels, used as incubators, and fluidic connectors, all mounted on a breadboard type base, with polytetrafluroethane (PTFE) connectors. All components were fabricated from polymethylmethacrylate (PMMA) with duplicates prepared in polyetheretherketone (PEEK) to provide chemical resistance if required.

Two types of mixer systems were used in the experimental procedure. The first chip design (Figure 1A) was an interdigitated mixer, chosen to maximize mixing efficiency (Leung and others 2005), with $50 \mu \mathrm{m}$-interlaced fingers, which converged over a lower flow channel $100 \mu \mathrm{m}$ wide. The 2 nd was a simple y-device, with flows from the 2 inlets converging into a single outlet stream. Additionally, a number of fixed volume serpentine flow cells with an internal volume of $100 \mu \mathrm{L}$ were used to give a final incubation volume of 400 $\mu \mathrm{L}$ an incubator for the assay (Figure $1 \mathrm{~B}$ ).

A schematic of the final system design is shown in Figure 2, and a photograph of the assembled breadboard reactor system and the ocean optics flow cell (not used) and the cuvette system for offline absorbance detection is shown in Figure 3.

\section{Detection system}

The endpoint of the assay was determined by absorbance spectrometry. An Ocean Optics (Dunedin, Fla., U.S.A.) USB4000-UV-VIS miniature spectrometer was used combined with a 10 -mm cuvette holder and a DT-MINI-2-GS Deuterium/Tungsten Halogen Light Source to provide illumination over a range of 200 to $1000 \mathrm{~nm}$. An ocean-optics Z-style absorbance FIA flow cell was also obtained for use with the microassay; however, complications in its integration limited the usefulness of this device. These systems can be seen in the lower portion of Figure 3.

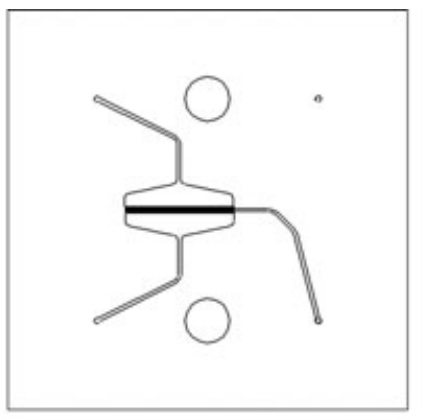

(A) Schematic of inter-digitated micromixer design.

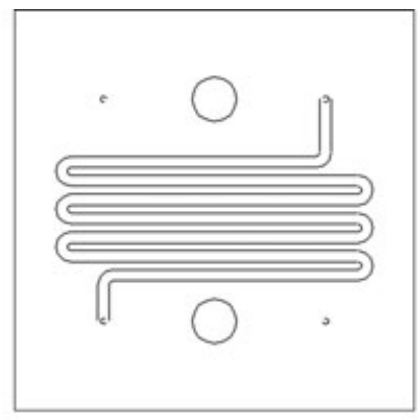

Figure 1 - Illustrations of the reactor devices used in the system. 


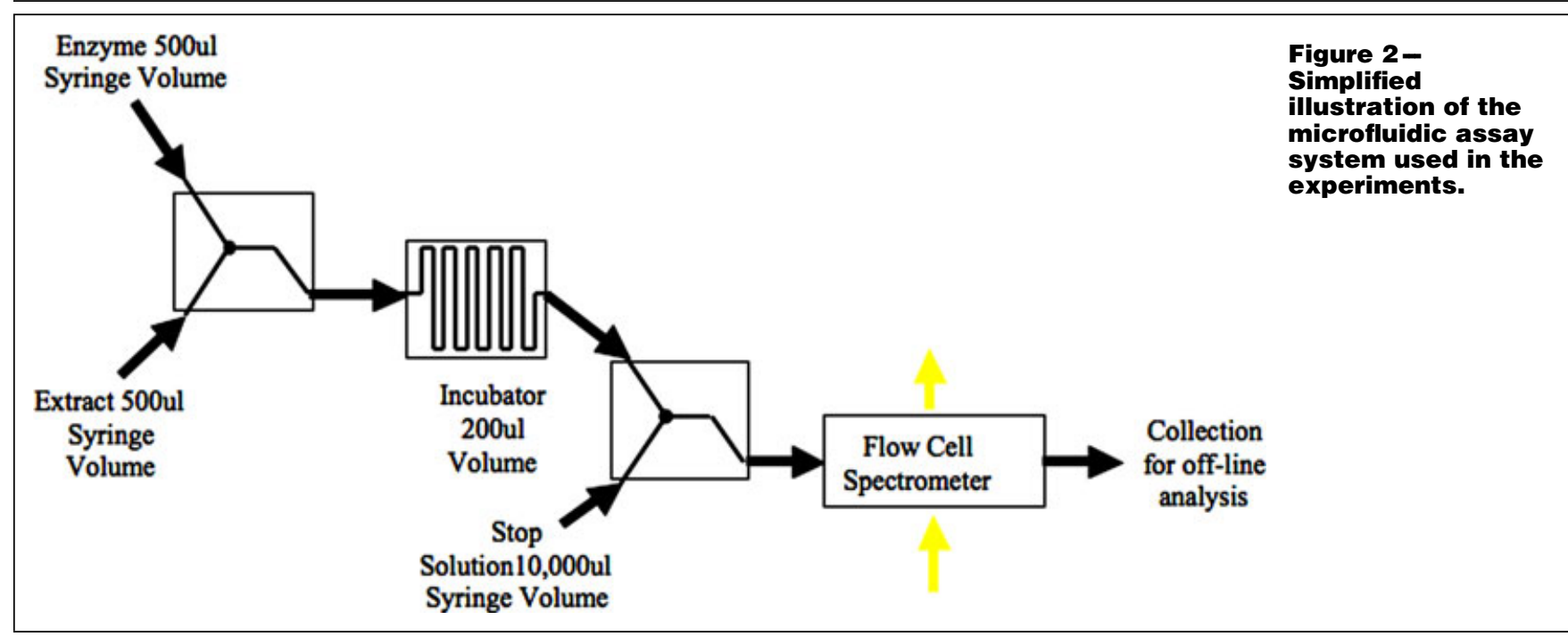

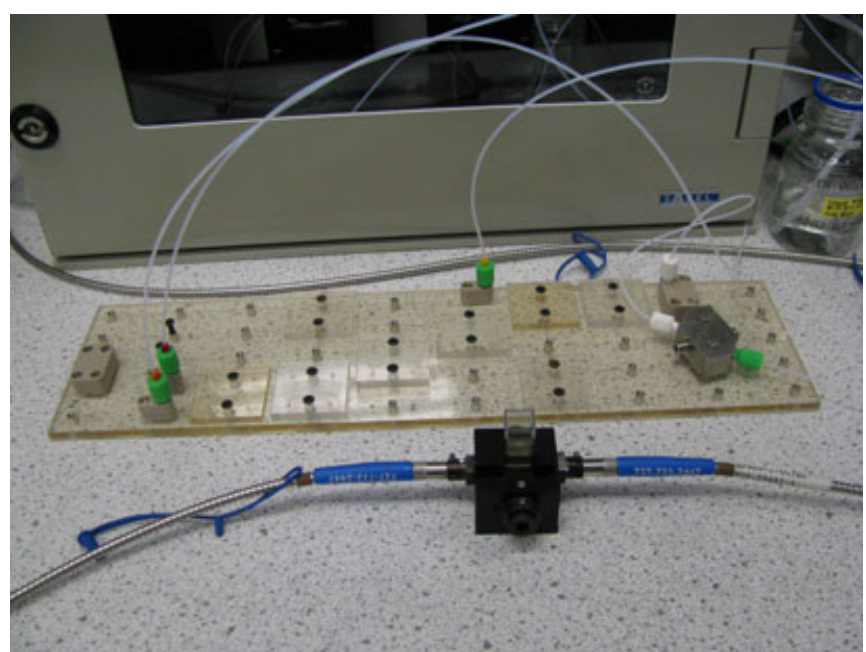

Figure 3-Photograph of the bread-boarded microreactor system and offline ocean-optics cuvette system.

\section{Fluid delivery system}

The reagent delivery system (Figure 4) comprised 3 Kloehn 55021-V6 precision syringe pumps with a full motion transit of 48000 steps, and a minimum step speed of 60 steps per second. Each pump was fitted with a 4-way distribution valve, and 2 of the pumps housed $500 \mu \mathrm{L}$ calibrated syringes delivering reagents to the reactor system. The 3rd V6 pump was fitted with a $10 \mathrm{~mL}$ calibrated syringe, used to delivery the sodium phosphate stop solution. The system also consisted of a 4th pump, which was not used in this procedure.

Four rail-mounted 24V Puls Miniline PSU's (RS Components Ltd, Northants, U.K.) provided the drive voltage for the syringe pumps. The reagent delivery system was housed in a Thalassa enclosure with a glass front (RS Components). Mounting of the syringe pumps inside the enclosure on antivibration mounts prevents vibration and cross-talk between syringes, as this can cause significant problems when running at low flow rates, mainly in terms of noise. A $24 \mathrm{~V}$ case fan and an air vent were mounted in the sides of the system to cool the syringe pumps, and a one of the Puls Miniline PSU's was tapped to provide a drive voltage for the fan.

The enclosure type was selected to allow the system to operate within a sealed container to allow for ease of transportation and observation of the internal workings, due to the large front window

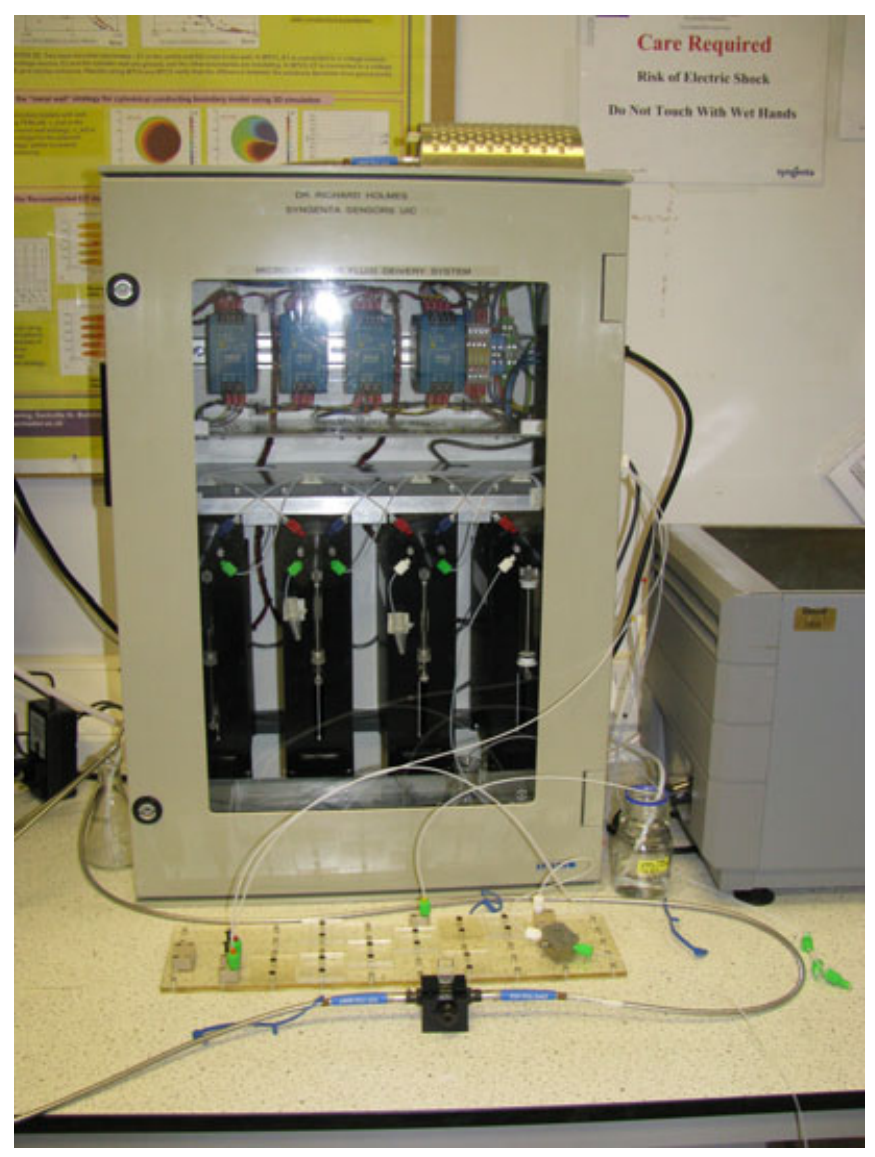

Figure 4-Photograph of the assembled prototype fluid delivery system, with the microfluidic breadboard system shown in the lower portion of the photograph.

present in the enclosure. Safety considerations based on the proximity of electronic components and fluidics meant that the Thalassa enclosure was divided into 2 sections, the upper containing the electronic components, the lower section containing the syringe pumps. In this way, all electrical components are isolated from any potential spillages or leaks.

The system was controlled using a standard PC running a program written by BJTB, and using the Natl. Instruments' LabVIEW (Natl. Instruments Corp., Austin, Tex., U.S.A.) development environment. 


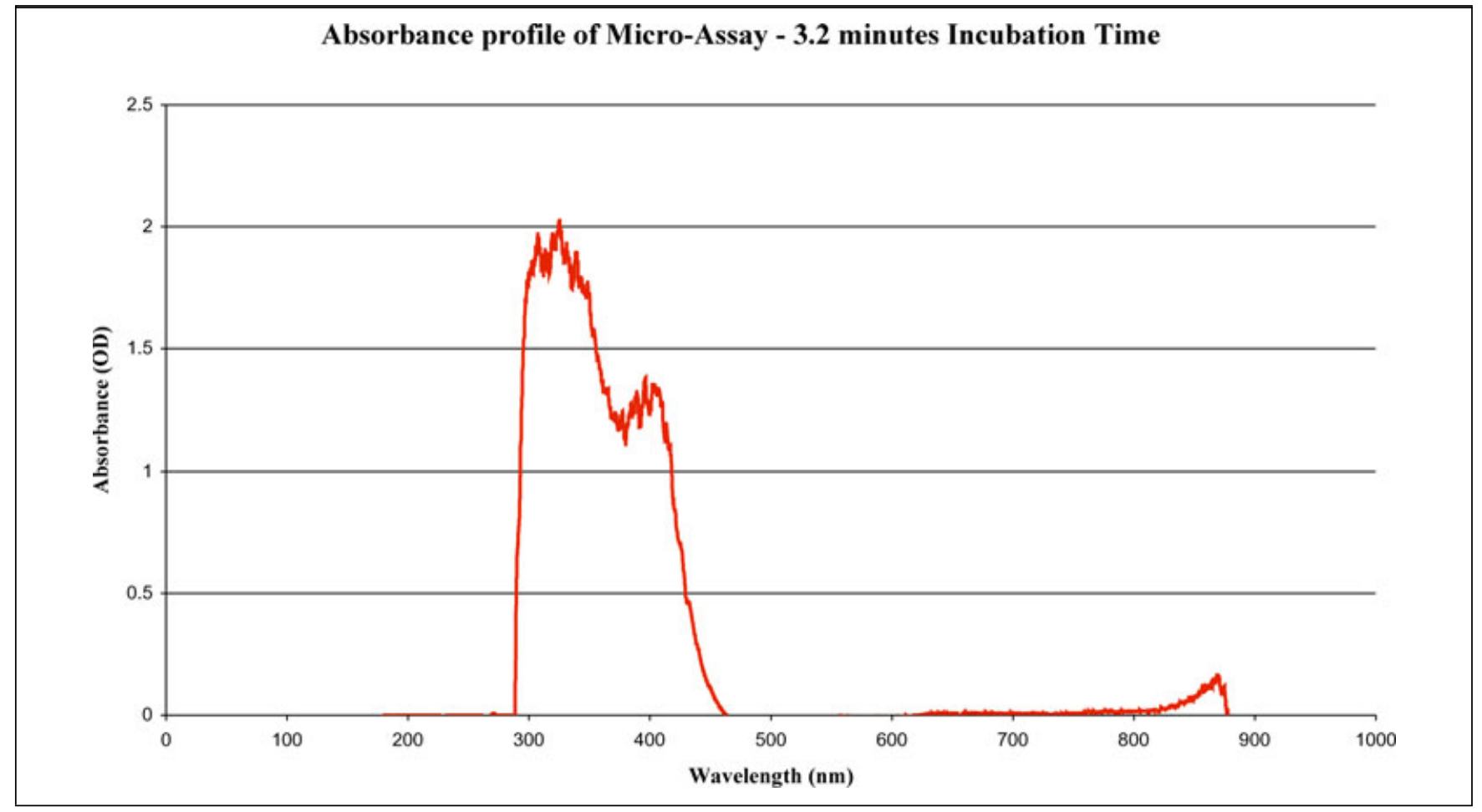

Figure 5-Typical response from the offline spectrometer following a 3.2-min incubation period for the microassay system, using the interdigitated micromixer systems upstream and downstream of the incubator.

Since the assay was conducted at $60^{\circ} \mathrm{C}$, the reactor board was immersed in a Grant SUB36 water bath (Grant Instruments Ltd, Cambridgeshire, U.K.) maintained at $60^{\circ} \mathrm{C}$ for the duration of the assay. The incubation time for the assay was the time taken for the reagents to traverse the incubator system. With flow rates at the incubator being equal to $125 \mu \mathrm{L} / \mathrm{min}$ and a $400 \mathrm{~mL}$ incubator installed, this made the incubation time for the assay equivalent to $3.2 \mathrm{~min}$.

\section{Results}

$\mathrm{T}$ he purpose of the experimental data obtained for this article was to demonstrate the application of microsystems technology to a routine biochemical assay procedure, the analysis of amylase concentration. Initial work focused on establishing the operating parameters of the assay procedure both in micro- and macroscale formats.

An ocean optics spectrometer was used to determine the endpoint of the amylase/PNP reaction, The spectrometer was configured for absorbance measurements, with an integration time of $100 \mathrm{~ms}$, and boxcar averaging value of 2 .

A typical response from the offline spectrometer following a 3.2-min incubation period for the microassay system, using the interdigitated micromixer systems upstream and downstream of the incubator is shown in Figure 5. The chart is plotted to illustrate wavelength response in nanometers compared with absorbance, measured as a function of optical density (OD) for the sample.

This indicates a significant peak in the absorbance at $400 \mathrm{~nm}$, corresponding to the presence of para-nitro phenol (PNP), which is released from the assay mix by the action of amylase. The larger peak at approximately $300 \mathrm{~nm}$ is indicative of the assay composition, and the bound PNP reagent, prior to release by amylase.

This indicates that a response of approximately $1.29 \mathrm{OD}$ at $400 \mathrm{~nm}$ is obtained using this system; however, there was a predilection for blockages developing in this device. It was found that at room temperature there were no issues with blockage formation; however, at the $60{ }^{\circ} \mathrm{C}$, the incubation temperature, the

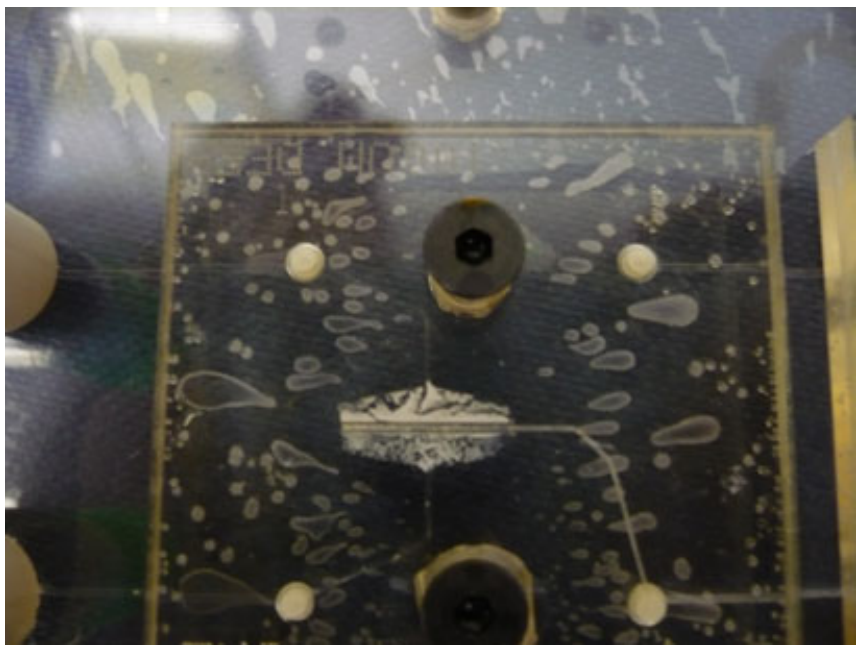

Figure 6-Interdigitated micromixer system, blocked with white precipitate (image taken of submerged device).

Table 1 - Experimental data for Cerealpha assay calculations.

\begin{tabular}{lcc}
\hline & Macro assay & Microreactor assay \\
\hline Assay volume & $0.2 \mathrm{~mL}$ & $0.5 \mathrm{~mL}$ \\
Aliquot volume & $3.4 \mathrm{~mL}$ & $11 \mathrm{~mL}$ \\
$E_{m M}$ & 18.1 & 18.1 \\
Incubation time & $20 \mathrm{~min}$ & $3.2 \mathrm{~min}$ \\
\hline
\end{tabular}

devices rapidly blocked with a white deposit—identified by mass spectrometery as being the major constituent of the Megazyme assay reagent. Repeated experimental runs demonstrated that a maximum of 3 assays could be conducted before the deposition reached a level that blocked the $50 \mu \mathrm{m}$ interdigitated fingers of 
Microfluidic-based rapid amylase assay system...

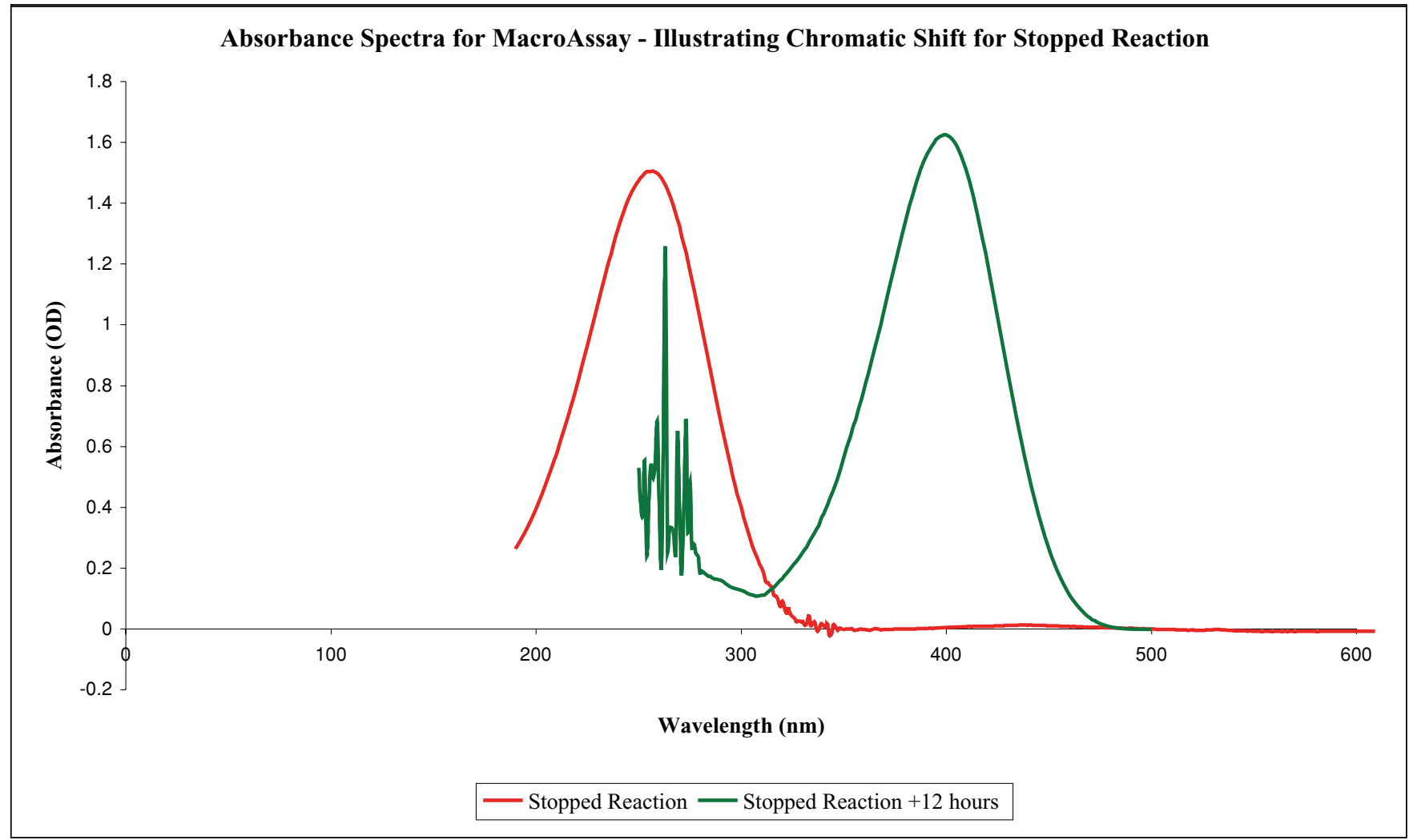

Figure 7 - Illustration of chromatic shift at room temperature for stopped reaction $\left(T_{0}\right)$.

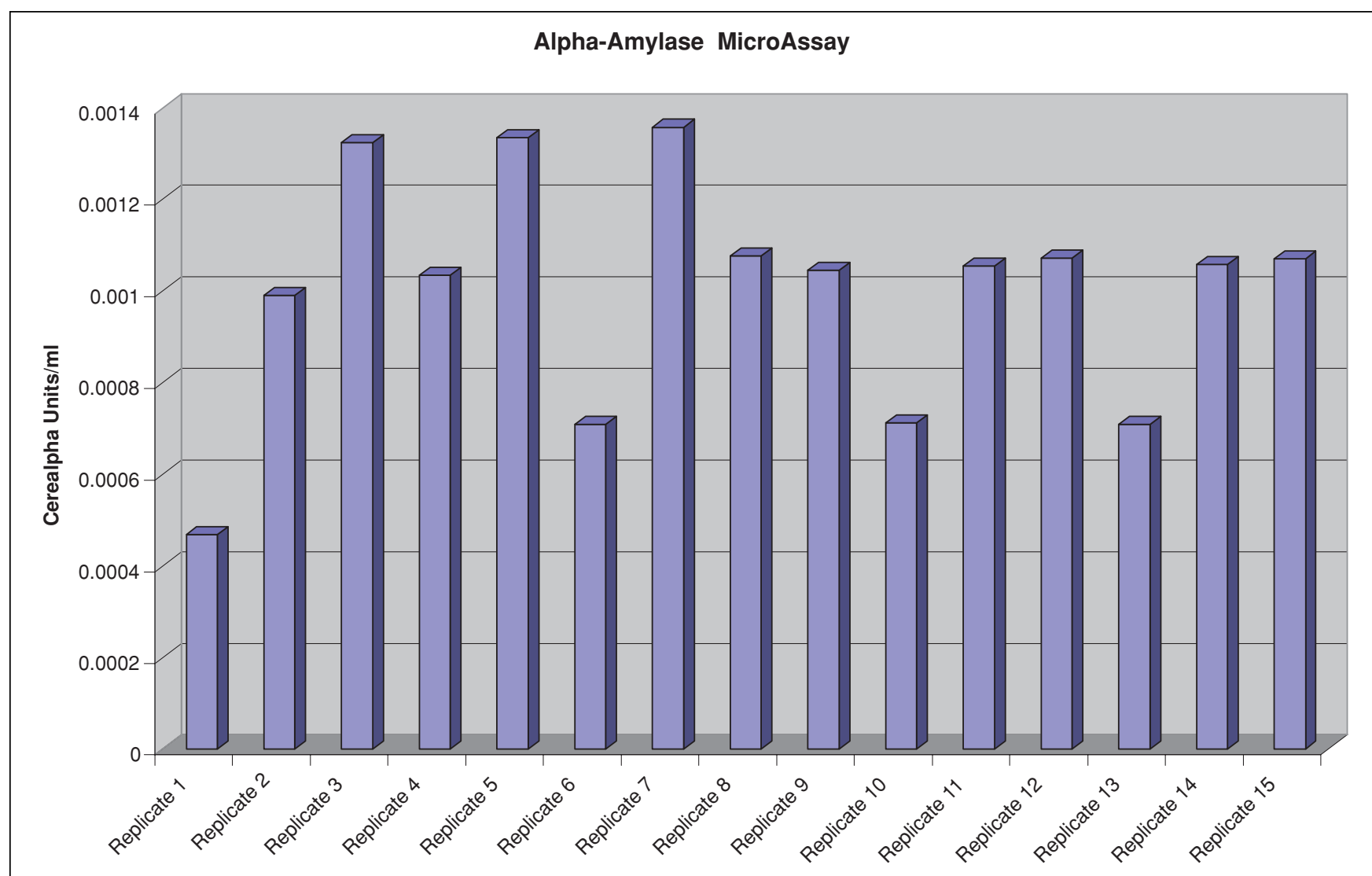

Figure 8-Graphical representation of 15 replicate microreactor assay data sets collected with an interdigitated micromixer converted into Cerealpha units detected per milliliter of sample. 


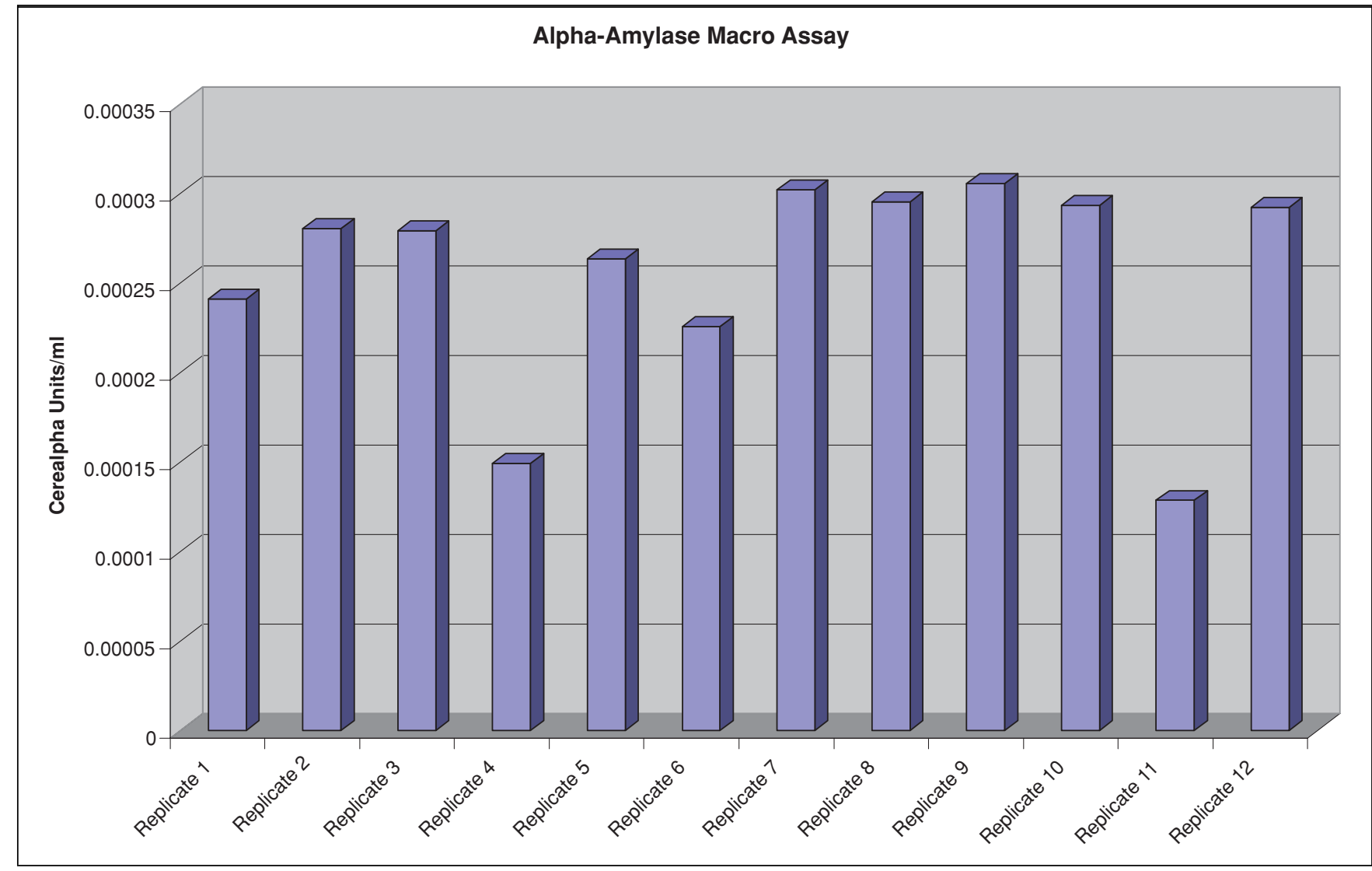

Figure 9-Graphical representation of replicate macro assay data sets collected converted into Cerealpha units detected per milliliter of sample.

the micromixer (Figure 6). After 3 experimental runs, the blocked micromixer device was replaced by a fresh component, and the experiments repeated to provide the data shown in Figure 8.

\section{Calculations of Cerealpha activity units}

One Cerealpha unit (CU) of $\alpha$-amylase activity is defined as the amount of enzyme, in the presence of excess thermostable $\alpha$ glucosidase, required to release $1 \mu \mathrm{mol}$ of p-nitrophenol in $1 \mathrm{~min}$ under the defined assay conditions, and the activity is measured in Cerealpha units.

$$
\begin{aligned}
\text { CerealphaUnits }(\mathrm{CU} / \mathrm{mL})= & \frac{\text { AssayAbs }_{400 \mathrm{~nm}}-\text { BlankAbs }_{400 \mathrm{~nm}}}{\text { IncubationTime }} \\
& \times \frac{\text { AssayVol }}{\text { AliquotVol }} \times \frac{1}{E_{\mathrm{mM}}} \times \text { Dilution }
\end{aligned}
$$

The various items are defined in Table 1.

The data in Figure 7 illustrate the color shift observed at assay termination-with the peak at $300 \mathrm{~nm}$ initially generated. This peak shifts over time, leaving a peak at $400 \mathrm{~nm}$ after approximately $12 \mathrm{~h}$ incubation at room temperature. Since it can be assumed that elevated temperatures increase the reaction rate, this shift would be observed in a 20 -min incubation period at $60^{\circ} \mathrm{C}$.

As such, the standard experimental protocol requires a baseline correction, to minimize this effect. The mean background correction of the macroassay was measured at $0.140 \mathrm{D}$. The 3.2-min incubation presented a slightly elevated background correction of $0.25 \mathrm{OD}$. This results from the baseline assay being conducted using a standard fluidic arrangement with the assay running at room temperature.

\section{Assay data}

Assay absorbency data were collected for 15 replicates of the microassay, and 12 replicates of the macroassay. The absorbance intensities were converted into Cerealpha units (CU) using the formulas in Eq. 1. The enzyme activity data were plotted (Figure 8), where it can be seen that the activity is not uniform; however, calculations showed that the response of the microassay system has an average response which is $1.0 \times 10^{-3} \mathrm{CU} / \mathrm{mL}$, with an SD of $2.5 \times 10^{-4} \mathrm{CU} / \mathrm{mL}$.

This data were compared to standard macroassay data. It can be seen in Figure 9 that the enzyme activity response of the standard 20-min assay conducted at $60^{\circ} \mathrm{C}$ presents a typical response of $2.5 \times 10^{-4} \mathrm{CU} / \mathrm{mL}$, with a significantly smaller SD $\left(5.9 \times 10^{-5}\right.$ $\mathrm{CU} / \mathrm{mL}$ ) than the microassay system.

\section{Conclusions}

7 his article describes our initial work into the development of a microfluidic bioreactor for enzyme assays. We have investigated a system (the amylase assay), which is of great interest to a number of commercial and research entities and developed a working system which not only provides a rapid assay system but which also enhances the sensitivity of the system when compared to the traditional laboratory microtitre plate assay. A decrease in assay duration of a factor of 6.2 , from 20 to $3.2 \mathrm{~min}$ indicated the benefits that microsystems technology and microreactors can offer in the bioassay arena.

The significant decrease in reaction time can be accounted for by the design of the microreactor mixer system, which utilizes laminar flow, diffusion limited mixing, and chaotic mixing to improve the mixing efficiencies, as indicated by the articles referenced in previous sections. 
The actual time frame under investigation was to all intents and purposes an arbitrary decision, based on the relative volumes of a number of the individual microreactor components. The full reactor board was constructed in such as manner as to provide a 3.2-min reaction time frame, with the potential increase or decrease this reaction time if the need arose, by the use of additional flow components or by adjusting flow rates. In the microreactor system, the time frame was quantified as the transit time taken for the reagents to traverse the complete reactor schematic, up to the point where the reaction was terminated, which was assumed to be instantaneous.

The macroscale reaction on the other hand utilizes a fixed volume system, incubated for a fixed time period, as detailed by the reaction schematics provided by Megayme Inc. The time frame in question for the macroscale reaction was taken as the incubation time for the reagents in a hot water bath, with the termination reagent added after the elapse of 20 min incubation at $60^{\circ} \mathrm{C}$. Additional time considerations for the addition of termination reagents and the associated mixing were not included into the reaction parameters, and it was assumed due to the vigorous nature of agitation with the termination reagent that termination in the macroassay system occurred instantaneously.

Basing the conclusion on the Megazyme Cerealpha Standard Method, and using the Cerealpha units as a measure of assay efficiency, the typical response for the microfluidic assay was shown to be $1.0 \times 10^{-3} \mathrm{CU} / \mathrm{mL}$ (SD $2.5 \times 10^{-4} \mathrm{CU} / \mathrm{mL}$ ), compared to $2.56 \times$ $10^{-4} \mathrm{CU} / \mathrm{mL}$ (SD $5.94 \times 10^{-5} \mathrm{CU} / \mathrm{mL}$ ) for the standard macroassay. This increase in sensitivity was obtained by the use of an interdigitated mixer system, which maximizes mixing efficiency in the reactor device (Daridon and others 2001), facilitating the completion of the assay far faster than with the macroscale reaction; however, this was at the expense of the device lifetime, which blocked after 3 sequential assay runs. The accumulation of these blockages could account for the degree of variability in the microreactor assay; however, overall a significant number of comparable replicate data sets were obtained.

While methods exist which can limit or even prevent the formation of this blockage, such as the use of a surface modification to the reactor, changes in reactor design, or the development of a disposable system. It was decided that for this initial investigation, the development of complex surface coatings or replacement devices was impractical. As such, it is believed by the authors that the data generated in this study could be significantly improved by the future development of a blockage-free microreactor.

The SD of the assay results is large when compared to the existing assay protocol; however, this is an area where significant improvements can be made once the issues mentioned previously have been resolved.

It should be stressed that the work presented here is initial conclusions only, the large SD values seen with the assay, and the problems associated with the depositions in the channels require further investigation. However, the generation of data that correlate with the existing standard assay offers significant potential for the future generation of microfluidic bioassay systems based on this concept.

\section{Acknowledgments}

The authors would like to thank the staff in the Satake Centre for Grain Production Engineering (SCGPE) at The School of Chemical
Engineering and Analytical Science, and the Sensing, Instrumentation and Signal Processing Group (SISP) in Electrical, and Electronic Engineering at The Univ. of Manchester for their support during the study.

\section{References}

$\alpha$-Amylase Assay Procedure (Ceralpha method): Icc Standard no. 303, Megazyme Intl. Ireland Ltd., Bray Business Park, Bray, Co. Wicklow, Ireland, 2008.

Bogdanovic J, Koets M, Sander I, Wouters I, Meijster T, Heederik D, van Amerongen A Doekes G. 2006. Rapid detection of fungal a-amylase in the work environment with a lateral flow immunoassay. J Allergy Clin Immunol 118(5):1158-63.

Cochran B, Lunday D, Miskevich F. 2008. Kinetic analysis of amylase using quantitative benedict's and iodine starch reagents. J Chem Educ 85(3):401-3.

Cowen S. 1999. Chip service. Chem Ind 584-6.

Craston D, Cowen S. 1996. Processing on a Chip. Chem Br 30(10):31-3.

Daridon A, Sequeira M, Pennarun-Thomas G, Dirac H, Krog JP, Gravesen P, Lichtenberg J, Diamondb D, Verpoortea Elisabeth, de Rooija NF. 2001. Chemical sensing using an integrated microfluidic system based on the Berthelot reaction. Sens Actuators B Chem 76:235-43.

de Mello A, Wooten R. 2002. But what is it good for? Applications of microreactor technology for the fine chemical industry-a review of developments in microreactor technology. Lab Chip 2:7N-13N.

DeMello AJ. 2006. Control and Detection of Chemical reactions in microfludic systems. Nature 442:394-402.

Doku GN, Haswell SJ. 1998. Micro-analytical (mFIA) reactor for the determination of phosphate as orthophosphate. In: Harrison DJ, van den Burg A, editors. Micro total analysis systems 1998. Dordrecht: Kluwer Academic Publishers. p 3514 .

Ebrahimi F, Khanahmadi M, Roodpeyma S, Taherzadeh MJ. 2008. Ethanol production from bread residues. Biomass \& Bioenergy 32(4):333-7.

Foo AY, Bais R. 1998. Amylase measurement with 2-chloro-4-nitrophenyl maltotrioside as substrate. Clinica Chimica Acta 272:137-47.

Gibson TS, Solah VA, McCleary BV. 1994. Quantitative measurements of total starch in cereal flours and products. J Cereal Sci 20:51-8.

Gibson TS, Solah VA, McCleary BV. 1997. A procedure to measure amylose in cereal starches and flours with concanavalin A. J Cereal Sci 25:111-9.

Gogoir BK, Bezbaruahk L, Pillai R, Baruah JN. 1987. Production, purification and characterization of an a-amylase produced by Saccharomycopsis Fibdigera. J Appl Bacteriol 63:373-9.

Greenway GM, Haswell SJ, Morgan DO, Skelton V, Styring P. 2000. The use of a novel microreactor for high throughput continuous flow organic synthesis. Sens Actuators B Chem 63:153-8.

Jeon BY, Kim DH, Na BK, Ahn DH, Park DH. 2008. Production of ethanol directly from potato starch by mixed culture of Saccharomyces cerevisiae and Aspergillus niger using electrochemical bioreactor. J Microbiol Biotechnol 18(3):54551 .

Kaneko T, Ohno T, Ohisa N. 2005. Purification and characterization of a thermostable raw starch digesting amylase from a streptomyces $\mathrm{sp}$. isolated in a milling factory. J Biosci Biotechnol \& Biochem 69(6):1073-81.

Kaufman RA, Tletz NW. 1980. Recent advances in measurement of amylase activity-a comparative study. J Clin Chem C 26(7):846-53.

Leung SA, Winkle RF, Wootton RCR, de Mello AJ. 2005. A method for rapid reaction optimisation in continuous-flow microfluidic reactors using online Raman spectroscopic detection. The Analyst 130:46-51.

Maeda E, Kataoka M, Yatsushiro S, Kajimoto K, Hino M, Kaji N, Tokeshi M, Bando M, Kido J, Ishikawa M, Shinohara Y, Baba Y. 2008. Accurate quantitation of salivary and pancreatic amylase activities in human plasma by microchip electrophoretic separation of the substrates and hydrolysates coupled with immunoinhibition. Electrophoresis 29(9):1902-9.

McCleary BV, Sheehan H. 1987. Measurement of cereal a-amylase: a new assay procedure. J Cereal Sci 6:237-51.

Min RW, Carlsen M, Nielsen J, Villadsen J. 1995. Measurement of a-amylase activity by sequential injection analysis. Biotechnol Tech 9(10):763-6.

Mojovic L, Nikolić S, Rakin M, Vukasinovic M. 2006. Production of bioethanol from corn meal hydrolyzates. Fuel 85:1750-5.

Pennathur S. 2008. Flow control in microfluidics: are the workhorse flows adequate? Lab Chip 8:383-7.

Rader JI, Weaver CM, Angyal G. 1998. Use of a microbiological assay with tri-enzyme extraction for measurement of pre-fortification levels of folates in enriched cerealgrain products. Food Chem 62(4):451-65.

Robinson LH, Juttner J, Milligan A, Lahnstein J, Eglinton JK, Evans DE. 2007. The identification of a barley haze active protein that influences beer haze stability: cloning and characterisation of the barley SE protein as a barley trypsin inhibitor of the chloroform/methanol type. J Cereal Sci 45(3):34352.

Sadowski J, MacGregor A, Daussant J. 1986. Alpha-amylase inhibitor in cereals: comparison of the protein in different rye, wheat and triticale seeds by using immunoblotting. Electrophoresis 7:176-9.

Sheehan H, McCleary BV. 1988. A new procedure for the measurement of fungal and bacterial a-amylase. Biotechnol Tech 2:289-92.

Sirou Y, Lecommandeur D, LauriBre' C. 1990. Specific enzymatic microassays of aamylase and \&amylase in cereals. J Agric Food Chem 38:171-4.

Stroock AD. 2002. Chaotic mixer for microchannels. Science 295:647-51. 